\title{
Unilateral Diaphragmatic Agenesis with Lung Cyst Herniating into the Abdomen Precluding Diaphragmatic Hernia in an Adult
}

\author{
Binay Krishna Sarkar ${ }^{1}$, Krishnendu Chakravorty $^{1}$, Ashis Halder ${ }^{1}$, Paresh Banerjee ${ }^{1}$, \\ Saroja Bharati2,3,4 \\ ${ }^{1}$ Department of Cardiovascular \& Thoracic Surgery, Nil Ratan Sircar Medical College \& Hospital, Kolkata, India \\ ${ }^{2}$ Rush University Medical Center, Chicago, IL, USA \\ ${ }^{3}$ University of Illinois College of Medicine, Chicago, IL, USA \\ ${ }^{4}$ Advocate Children's Hospital and Advocate Christ Medical Center, Oak Lawn, IL, USA \\ Email: bappa_2k1_bk@yahoo.co.in, binayskr@hotmail.com
}

How to cite this paper: Sarkar, B.K., Chakravorty, K., Halder, A., Banerjee, P. and Bharati, S. (2016) Unilateral Diaphragmatic Agenesis with Lung Cyst Herniating into the Abdomen Precluding Diaphragmatic Hernia in an Adult. World Journal of Cardiovascular Surgery, 6, 171-175. http://dx.doi.org/10.4236/wjcs.2016.611023

Received: August 10, 2016

Accepted: November 27, 2016

Published: November 30, 2016

Copyright $\odot 2016$ by authors and Scientific Research Publishing Inc. This work is licensed under the Creative Commons Attribution International License (CC BY 4.0).

http://creativecommons.org/licenses/by/4.0/ (c) (i) Open Access

\begin{abstract}
Background: Diaphragmatic agenesis or complete absence of a hemidiaphragm in adulthood is rare. The significance of presence of a lung cyst occupying the common thoracoabdominal space lies in the absence of associated diaphragmatic hernia which has not been documented previously. Case Presentation: We report a case of previously undiagnosed complete absence of a hemidiaphragm in a 62-year-old male who presented with recurrent respiratory infection, episodes of nausea and postprandial fullness. Computed Tomography scan showed a large cyst in relation to the lower lobe of left lung. During surgery, he was found to have complete absence of a left hemidiaphragm and a large cyst arising from the lower lobe of left lung occupied the common thoracoabdominal space. Abdominal viscera were found displaced downwards and fixed in a thick fibrous membrane. There was no herniation of abdominal organs into the thoracic cavity after excision of the cyst. The left lung could be fully expanded and chest was closed after putting a chest drain. Diaphragmatic agenesis did not require any additional procedure. The cyst was excised with closure of bronchocystic opening. The patient had an uneventful recovery. Conclusions: The association of lung cyst with diaphragmatic agenesis (presented in the adulthood) is rare. It has precluded a diaphragmatic hernia and survived the patient acting as a protective barrier. The significance of lung cyst in presence of diaphragmatic agenesis lies in the absence of associated diaphragmatic hernia which has not been documented previously.
\end{abstract}

\section{Keywords}

Lung Cyst, Absent Hemidiaphragm, Recurrent Respiratory Infection 


\section{Introduction}

Diaphragmatic agenesis or complete absence of a hemidiaphragm in adulthood is rare [1] [2] [3] [4]. It is reported to be about $6 \%$ of all Congenital Diaphragmatic Hernia $(\mathrm{CDH})$ [5]. Congenital diaphragmatic hernia $(\mathrm{CDH})$ is a congenital malformation of diaphragm, where gastro-intestinal loops and other abdominal viscera herniate into the thoracic cavity through a defect in the diaphragm. In extreme form of diaphragmatic maldevelopment, there may be a complete agenesis of diaphragm. It may remain asymptomatic for decades [6] [7]. Diaphragmatic agenesis is usually associated with herniation of gastro-intestinal loops and other abdominal viscera into the thoracic cavity [2] [3] [4]. Patient may come with respiratory and/or gastrointestinal symptoms and even strangulation of gut. We present a case of agenesis of left hemidiaphragm in a 62-year-old male who came with recurrent respiratory infection but without diaphragmatic hernia. He was found to have complete absence of a left hemidiaphragm and a large cyst arising from the lower lobe of left lung occupying common thoracoabdominal space thus created.

\section{Case Report}

A 62-yr-old man, presented to our hospital with the history of recurrent respiratory tract infection, upper abdominal pain and upper abdominal discomfort. He also complained of episodes of nausea and postprandial fullness. He was referred to our department with the diagnosis of diaphragmatic hernia.

On admission, he was stable in room air. Physical examination showed absent breath sounds and dull to percussion findings at the left lower chest. The chest radiography revealed a well-defined air filled structure in relation to lower part of left lung.

However, Barium meal stomach shows stomach in its intraabdominal position. Computed Tomography scan showed a large cyst in the left lower hemithorax in relation to the lower lobe of left lung which showed extension into the upper abdomen (Figure 1 and Figure 2).

The patient underwent surgical exploration. During surgery, he was found to have complete absence of a left hemidiaphragm and a large cyst arising from the lower lobe of left lung occupies the common thoracoabdominal space displacing the abdominal viscera downwards which were lying fixed to the abdominal wall in a thick fibrous membrane (Figure 3).

\section{Surgical Procedure}

Left posterolateral thoracotomy was done under general anesthesia to open left hemithorax. Multiple dense adhesions were found and left lung was freed from chest wall and pericardium after adhesionolysis. After careful dissection, a large cystic structure was found in relation to the lower lobe of left lung. Diaphragm was found absent on the left side and the cyst was found extending down into the abdomen occupying the common thoracoabdominal space. The cyst was decompressed and completely dissected out from thoracoabdominal wall. Cyst wall was opened, excised, bronchocystic 


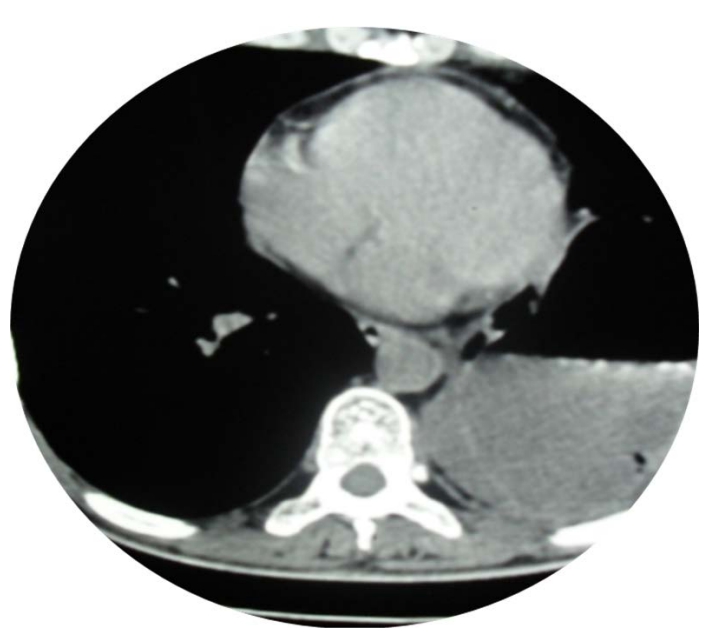

Figure 1. CT scan showing cyst occupying left hemithorax.

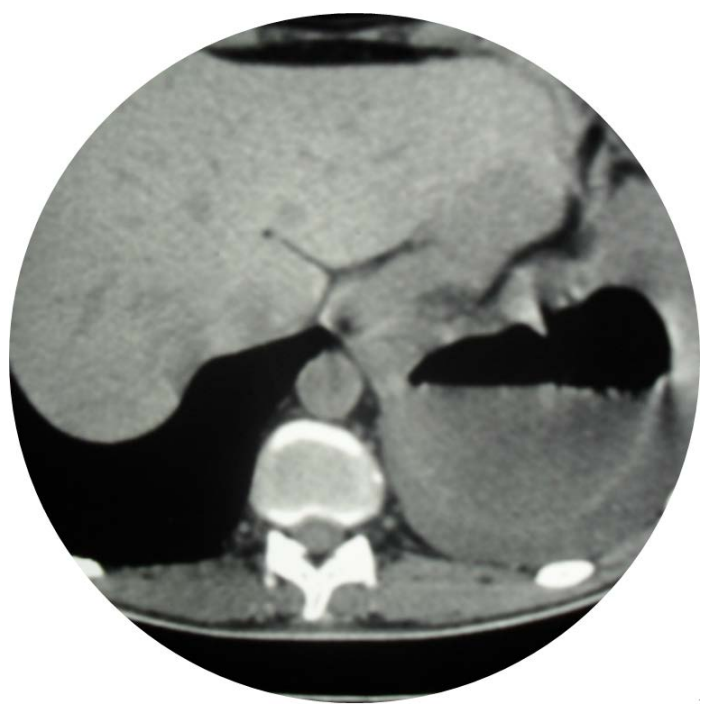

Figure 2. CT scan showing extension of the cyst lying inside upper abdomen.

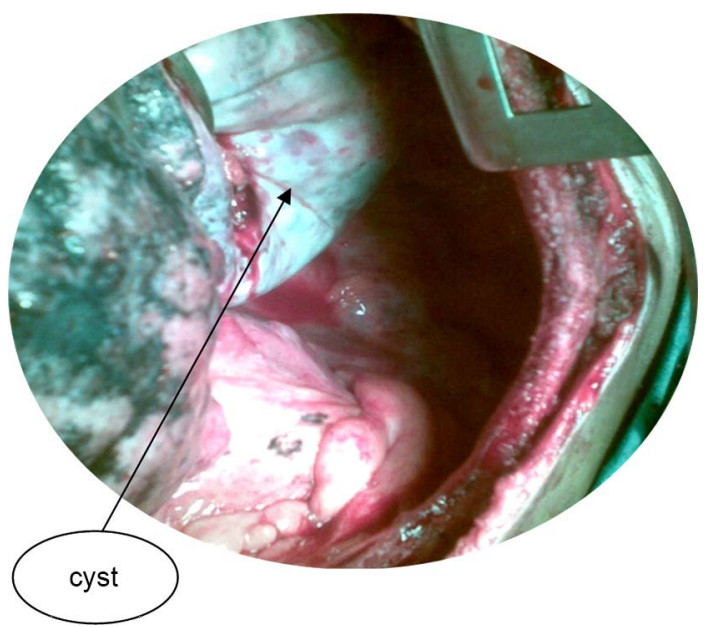

Figure 3. Cyst freed all around, fluid asprated, congenital absence of diaphragm. 
communications identified and closed. Cyst content was thick with necrotic debris. Adjacent Abdominal viscera were found displaced downwards in the abdominal cavity and fixed in a thick overlying fibrous membrane. There was no herniation of abdominal organs into the thoracic cavity. Diaphragmatic agenesis did not require any additional procedure. The left lung could be fully expanded and chest was closed after putting a chest drain.

Postoperative recovery was uneventful. Patient was well in the follow-up.

\section{Discussion}

Developmentally diaphragm originates from septum transversum, pleuroperitoneal membrane and the thoracic wall [4] [5] [6]. The gastrohepatic ligament and dorsal mesentery also contribute to its development. Agenesis of the hemidiaphragm involves non-development of all of these components. Congenital Hemi-Diaphragmatic Agenesis (CHDA) may be differentiated into partial and complete agenesis depending on the presence of diaphragmatic remnants [4]. Complete agenesis of diaphragm, usually involves one side, but, sometimes both sides. In case of complete diaphragmatic agenesis no diaphragmatic remnant is present whether in partial diaphragmatic agenesis; diaphragmatic remnants may be present especially on posterior aspects.

Cunniff et al. reported a $6 \%$ incidence of diaphragmatic agenesis in their review of 102 live born children with congenital diaphragmatic defects [5]. A failure of pleuroperitoneal membrane to close the pleuroperitoneal canal on the involved side was considered to be the probable etiology by some authors but others proposed a failure of all the precursors components of diaphragm to develop [1] [2] [4]. Environmental factors and various medications have been proposed to play a key role in development of the $\mathrm{CDH}$ in animal models.

Chest radiograph cannot specifically diagnose the CHDA but is a modality of choice in case of $\mathrm{CDH}$. Barium studies, CT scan and MRI are important diagnostic modalities for the diagnosis of the diaphragmatic abnormalities. CT scan and MRI are important diagnostic modalities for the delineation of the diaphragm and its abnormalities.

In case of symptomatic presentation, an early surgical intervention may be beneficial for the patient. The surgical repair of the lesion is very difficult owing to completely absent diaphragmatic tissue or if present not sufficient enough to accomplish the repair. Various authors used different treatment options including, prosthetic materials, abdominal wall and chest wall muscle flaps, suturing the chest margins with liver, use of pre-renal fascia and some advocated no repair at all [2] [4]. However, many cases with $\mathrm{CDH}$, treated with mesh incorporation in the defect, showed prosthesis related complications and even recurrence of the herniation [4].

In our case, presentation of diaphragmatic agenesis was late in the adulthood with respiratory and abdominal symptoms. Chest $\mathrm{x}$-ray revealed a structure with air-fluid level in the left hemithorax but Barium studies did not suggest diaphragmatic pathology. Computed Tomography scan showed a large cyst in relation to the lower lobe of left lung. On surgical exploration, he was found to have complete absence of a left 
hemidiaphragm and a large cyst arising from the lower lobe of left lung occupied the common thoracoabdominal space displacing the abdominal viscera downwards which were covered with thick fibrous membrane.

\section{Conclusion}

The absence of diaphragm had possibly allowed the lung cyst to enter into the abdomen and the cyst was a protective barrier for development of diaphragmatic hernia into the bony hemithorax. The patient had grown into adulthood without symptoms and survived to adulthood. The presence of pleuro-peritoneal adhesions may have played a role in preventing herniation. The presence of cyst into the abdomen had possibly initiated a chronic inflammatory process which resulted in the formation of a thick fibrous membrane over the displaced abdominal viscera and fixed the abdominal contents in a new position which helped the abdominal viscera to contain in the abdomen even after the excision of the cyst. Therefore, reconstruction of a new diaphragm to separate the thoracic and abdominal contents was not necessary. The expanded lung with compensatory hypertrophy was found to have taken care of the potential space below the lung.

\section{References}

[1] Toran, N. and Emery, J.L. (1981) Congenital Bilateral Absence of Diaphragm. Thorax, 36, 157-158. https://doi.org/10.1136/thx.36.2.157

[2] Sung, H.Y., Cho, S.H., Sim, S.B., Kim, J.I., Cheung, D.Y., Park, S.H., et al. (2009) Congenital Hemidiaphragmatic Agenesis Presenting as Reversible Mesenterioaxial Gastric Volvulus and Diaphragmatic Hernia: A Case Report. Journal of Korean Medical Science, 24, 517-519. https://doi.org/10.3346/jkms.2009.24.3.517

[3] Sheehan, J.J., Kearns, S.R., McNamara, D.A., Brennan, R.P. and Deasy, J.M. (2000) Adult Presentation of Agenesis of the Hemidiaphragm. Chest, 117, 901-902. https://doi.org/10.1378/chest.117.3.901

[4] Mirza, B., Bashir, Z. and Sheikh, A. (2012) Congenital Right Hemidiaphragmatic Agenesis. Lung India, 29, 53-55. https://doi.org/10.4103/0970-2113.92364

[5] Cunniff, C., Jones, K.L. and Jones, M.C. (1990) Patterns of Malformation in Children with Congenital Diaphragmatic Defects. Journal of Pediatrics, 116, 258-261. https://doi.org/10.1016/S0022-3476(05)82884-7

[6] Tzelepis, G.E., Ettensohn, D.B., Shapiro, B. and McCool, F.D. (1988) Unilateral Absence of the Diaphragm in an Asymptomatic Adult. Chest, 94, 1301-1303. https://doi.org/10.1378/chest.94.6.1301

[7] Wakai, A., Winter, D.C. and O’Sullivan, G.C. (2000) Unilateral Diaphragmatic Agenesis Precluding Laparoscopic Cholecystectomy. JSLS, 4, 259-261. 
Submit or recommend next manuscript to SCIRP and we will provide best service for you:

Accepting pre-submission inquiries through Email, Facebook, LinkedIn, Twitter, etc. A wide selection of journals (inclusive of 9 subjects, more than 200 journals)

Providing 24-hour high-quality service

User-friendly online submission system

Fair and swift peer-review system

Efficient typesetting and proofreading procedure

Display of the result of downloads and visits, as well as the number of cited articles

Maximum dissemination of your research work

Submit your manuscript at: http://papersubmission.scirp.org/

Or contactwjcs@scirp.org 